\title{
LA MAÑANA ESTÁ BONITA... Y LA CIUDAD TAMBIÉN: LA CIUDAD DE MÉXICO A LOS OJOS DE GUILLERMO SHERIDAN
}

Raúl Bravo Aduna*

RESUMEN: A partir de una deriva por los pasillos de las teorías psicogeográficas del Situacionismo francés, se presenta un análisis de la configuración de la ciudad de México en la obra del ensayista y académico Guillermo Sheridan, prestando particular atención a tres puntos específicos: lo misterioso y aterrador de una ciudad en la que lo anormal se sabe normal; la reconstrucción de identidad y personalidad por medio de una crítica incisiva al espacio urbano; la volatilidad y dificultad que implica pasear por una ciudad de México caótica y disímil.

PALABRAS Clave: Debord, psicogeografía, ciudad, espacio, situacionismo, Sheridan.
ABSTRACT: While wandering in the halls of French situationism's psychogeographic theories, we are presented with the opportunity to analyze Mexico City's infrastructure in the works of essayist and academic, Guillermo Sheridan. In this article, we will focus on the following three points: the city's mysterious and terrifying aspect where the abnormal is the norm, the reconstruction of its personality and identity through a harsh criticism of its urban space, and the instability and inconvenience of walking through this chaotic and cunning city.

KEYwORDS: Debord, psychogeography, city, space, situationism, Sheridan.

* Centro de Lenguas, Universidad Panamericana; editor de la revista Cuadrivio. 


\section{LA MAÑANA ESTÁ BONITA... Y LA CIUDAD TAMBIÉN: LA CIUDAD DE MÉXICO A LOS OJOS DE GUILLERMO SHERIDAN}

La ciudad es permanente, pero volátil; monolítica, pero maleable. Nada en ella es eterno y, sin embargo, todo en ella busca permanecer, no ser sometido a la tiranía del tiempo. Paradoja incomprensible, la ciudad, aunque objetiva (delimitada por planos, constituida por edificios específicos, registrada y administrada por catastros), es subjetividad pura: punto de encuentro de una miríada de miradas distintas sobre un supuesto mismo fenómeno, que en realidad puede tomar cualquier forma o significación posibles. La ciudad, por tanto, puede ser catalogada de muchísimas cosas, pero no de sencilla.

Desde su definición por Guy Debord en 1955, la psicogeografía se ha convertido en un punto de referencia obligado para el estudio de la concepción subjetiva de las ciudades (aunado a los conceptos de geography matters, geografía humana y geografía social, entre otros). Desde los adherentes a la Internacional situacionista a finales de los años cincuenta, hasta los revisionistas de las distintas teorías en que han ramificado desde Debord, ha habido un interés por amalgamar distintas esferas y capas de la experiencia urbana, para dar explicaciones más integrales y menos definitivas de la ciudad, delineadas por un marco teórico-psicogeográfico, buscando sustentarse en una geografía social, por un lado, y de lo efímero y transitorio, por el otro. Por su complejidad de análisis en el mundo "real", la psicogeografía re- 
curre con frecuencia a las representaciones literarias de las ciudades para sus empresas espeleológicas.

Aunque no de manera exclusiva, en literatura los análisis psicogeográficos de ciudades tienden a ser realizados sobre expresiones narrativas. Lo anterior es comprensible por el tipo de representación que suelen ofrecer novelas y cuentos, no sólo del espacio, sino del tiempo, sentimientos, objetos y demás elementos que constituyen el entramado narrativo. Precisamente, la polifonía de la narrativa da pie a que se puedan analizar las distintas capas y esferas que la psicogeografía busca observar de una ciudad. Sin embargo, lo mismo puede ser localizado en otros géneros, en el ensayo, por ejemplo, como se verá más adelante.

Si bien es cierto que toda ciudad es compleja, hay ciudades que son más complejas que otras... y después, más lejos todavía, está la ciudad de México: centauro ciempiés, ostión malformado, cucaracha kafkiana que también tiene algo de parisina (alguna vez escuché que París no es otra cosa que un montón de Bellas Artes amontonados), que también se convierte, de noche, en millardos de sílfides danzantes, lugar en el que se puede encontrar el amor entre calles sin nombres y barrios desfigurados, entre paquetes humanos y embotellamientos de autos. Aunque compli- cada e incontenible, la ciudad de México ha quedado delineada, en gran medida, por la poesía mexicana, que se ha encargado de intentar trazar el camino que ha seguido, como establece Claudia Kerik, a través del “desorden, la aparición simultánea de distintas visiones de la ciudad en los poemas, la confrontación de modos contradictorios de percepción de una misma ciudad". ${ }^{1}$

Salida de la pluma de Guillermo Sheridan (1950), cualquier palabra es diatriba en potencia, crítica en ciernes. A los ojos del humorista y académico mexicano, todo evento en México trae consigo la posibilidad de ser analizado a base de risas, un desmenuzamiento que revela terquedades $y$ absurdeces sociales entre risotada y risotada. Dada su ferviente religión a la poesía mexicana, no es de sorprender que algunas de las críticas más incisivas y punzantes de Sheridan tomen a la ciudad de México como blanco, precisamente por la importancia que ha tenido en su tradición. Ante los ojos de Sheridan, la ciudad de México se vuelve, en ocasiones, el peor lugar para vivir: un monstruo obtuso que no puede ser domesticado, en el cual su propia arquitectura lo vuelve más torpe y salvaje; sin embargo, el humor y la ironía de Sheridan

${ }^{1}$ Claudia Kerik, "Poesía y ciudad", Letras libres, en línea, Internet enero de 2007, disponible http://www.letraslibres.com. 
NOTAS

transmutan en una suerte de filtro que da cabida a una reflexión más integral de la ciudad, en la que no hay espacio para posturas ni inamovibles ni maniqueas. Puesto que en las representaciones de la ciudad de México de la producción ensayística de Guillermo Sheridan colisionan psicología y geografía, ${ }^{2}$ lo supuestamente objetivo con lo subjetivo, me parece un caso sugerente para ser revisado bajo la lupa psicogeográfica.

Actualmente, existe consenso entre los estudiosos, en torno a la psicogeografía, concepto referente a un conocimiento general de la teoría, utilizado con frecuencia en distintos ámbitos, tanto académicos como cotidianos. Sin embargo, antes de entrar al análisis psicogeográfico de la ciudad de México de Sheridan, valdría la pena recorrer los pasillos de la psicogeografía en sí, así como de algunas de sus derivaciones y compañeros de viaje.

Uno podría pensar que la primera precisión que se tendría que hacer para hablar de psicogeografía es sobre el concepto mismo de psicogeografía; sin embargo, considero ese camino equívoco y desviante. Para entender a la ciudad en un contexto psicogeográfico, primero hay que abordar a la ciudad en términos generales para

${ }^{2}$ Para no entrar en discusiones de teoría de los géneros, tomo la etiqueta genérica de "ensayo" para catalogar a la prosa no académica de Sheridan, excluyendo su única novela publicada, por cuestiones de practicidad. poder, a la postre, entender las representaciones literarias de ciudades específicas.

Ya he mencionado que la ciudad queda determinada por una combinación de objetividad y subjetividad; ahí reside la complejidad para entender el concepto de ciudad. En este sentido, la definición de diccionario resulta de gran provecho: "Conjunto de edificios y calles, regidos por un ayuntamiento, cuya población densa y numerosa se dedica por lo común a actividades no agrícolas". ${ }^{3}$ Tal definición es útil porque parece ser la misma noción generalizada de las ciudades: entes estáticos, cuadriculados por calles, encajonados por edificios, habitados por paquetes de personas que nada modifican, entes que sólo cambian de vez en vez y poco a poco; tal definición es útil porque es categóricamente errónea o exigua, por decir lo menos.

La ciudad, en tanto concepto, elude las cadenas de las definiciones. "Ninguna definición podrá aplicar para todas sus variaciones y ninguna descripción podrá cubrir todas sus transformaciones, desde el núcleo social embrionario hasta las formas más complejas de su madurez y la desintegración corporal de su edad", ${ }^{4}$

\footnotetext{
3 “Ciudad”, Diccionario de la lengua española, en línea, Internet, disponible http://www.rae.es.

${ }^{4}$ Lewis Mumford, The City in History, 1989, San Diego, Harcourt, p. 3. Las traducciones son mías, a menos que se especifique lo contrario.
} 
apunta Lewis Mumford, referente obligado en el estudio de la ciudad. Y el terreno se vuelve todavía más tembloroso cuando se incorporan conceptos como espacio y lugar-y cómo éstos se articulan de maneras específicas en la construcción de la experiencia urbana, a partir de cuestiones sociales, económicas, de género y relaciones de producción que, por cuestiones de practicidad, no serán contempladas en este lugar-. La idea, sin embargo, es clara: no es sencillo hablar ni de la ciudad ni de su progresión histórica ni de sus configuraciones en términos generales, salvo quizá en abstracto y de manera general.

La ciudad no es suma de elementos; es, por el contrario, yuxtaposición de perspectivas, encabalgamiento de mundos tanto físicos y tangibles, como etéreos e inefables. El problema de la definición de diccionario de "ciudad" radica en una limitación exagerada sobre qué es lo "real" de una ciudad. La opinión común afirmaría, en una primer instancia, que lo real de una ciudad queda definido por el "conjunto de edificios y calles..."; sin embargo, como bien escribe Jonathan Raban:

a ratos [...] la ciudad se vuelve suave; espera que se le imprima una identidad. Para bien o para mal, te invita a re-hacerla, consolidarla en una forma en la que puedas habitar. Tú igual. Decide quién eres y la ciudad tomará una forma fija a tu alrededor. Decide qué es y tu identidad será revelada como un punto especifico triangulado en un mapa. Las ciudades [...] son elásticas por naturaleza. Las podemos malear a nuestra imagen. ${ }^{5}$

Así pues, lo "real" de la ciudad no sólo se encuentra en lo físico, sino en el comportamiento de las personas que la habitan; paralelamente, esas personas constituyen a la ciudad en sí:

A veces puede parecer como si el estado mental de la ciudad -sus opiniones, sus actitudes, su propio sentido de existencia, su humor- le diera un caracter propio y específico. Lo que es real de las ciudades, por tanto, son también sus cualidades intangibles: sus atmósferas, sus personalidad, quizá. ${ }^{6}$

Y aunque lo ramplón y concreto, incluso brutal de la ciudad, suela imponerse sobre lo maleable, "la ciudad como la imaginamos, la ciudad suave de ilusión, mito, aspiración, pesadilla, es real, incluso más real, que la ciudad dura que podemos encontrar en mapas, estadísticas y monografías de sociología urbana,

${ }^{5}$ Jonathan Raban, Soft City, 1998, Londres, The Harvill Press, p. 3.

${ }^{6}$ Steve Pile, Real Cities: Modernity, Space and the Phantasmagorias of City Life, 2005, Londres, SAGE, p. 3. 
demografía y arquitectura". ${ }^{7}$ Objetividad y subjetividad se entremezclan en la ciudad, se encuentran en retroalimentación perpetua y es imposible saber dónde comienza una y termina la otra, hasta el punto en que los trazos del mapa personal y el mapa imparcial quedan trenzados.

La arquitectura de una ciudad queda sometida a esta paradoja también, particularmente por la interacción de las personas con ella. Al respecto, David Harvey establece: "nuestra experiencia subjetiva puede llevarnos a los terrenos de la percepción, imaginación, ficción y fantasía, que producen tantos espacios y mapas mentales como miradas del fenómeno supuestamente "real" ". ${ }^{8}$ Los edificios de la ciudad quedan impregnados por la ciudad misma, así como por la impresión que tiene el observador (París como un montón de Bellas Artes aglutinados). De tal manera, la arquitectura adquiere una doble función, como lo sugerido por el filósofo norteamericano Karsten Harries: por un lado, la arquitectura busca domesticar el espacio, dar una forma específica a las cosas; por el otro, desafía a la tiranía del tiempo, a través de la belleza adquiere un lenguaje supuestamente eterno. ${ }^{9} \mathrm{Sin}$

${ }^{7}$ Raban, op. cit., p. 4.

${ }^{8}$ David Harvey, The Condition of Postmodernity, 1992, Cambridge, MA, Blackwell, 203. Las itálicas son mías.

${ }^{9}$ Cfr. ibid., p. 206. embargo, ambas funciones quedan supeditadas al entendimiento de la arquitectura dentro de la ciudad que no puede ser contenida por una forma específica: no es objetiva, ni en cuanto a tiempo ni en cuanto a espacio (condición de perspectiva que ha quedado como la dominante desde la aparición del posmodernismo entendido en un sentido amplio). Por más que la arquitectura luche por demostrar lo contrario, en la ciudad la realidad está encadenada a ser desesperadamente imprecisa.

Dicho lo anterior, es posible movernos al terreno de la psicogeografía. En 1955 Guy Debord estableció que "la psicogeografía se proponía el estudio de las leyes precisas y de los efectos exactos del medio geográfico, conscientemente organizado o no, en función de su influencia directa sobre el comportamiento afectivo de los individuos". ${ }^{10}$ Es un concepto que queda algo abierto, ambigüedad que le gustaba al mismo Debord, para permitir un espectro más amplio de trabajo sobre lo psicogeográfico. Pero para Merlin Coverley lo psicogeográfico se caracteriza por tres elementos particulares: 1) el

${ }^{10}$ Guy Debord, "Introduction à une critique de la géographie urbaine", La Revue des Ressources, en línea, Internet octubre 2009, disponible http:// www.larevuedesressources.org. La traducción es de Lourdes Martínez para la revista Amano, disponible en el Archivo Situacionista Hispano en línea http://www.sindominio.net. 
acto de caminar o la deriva en el paisaje urbano, por ponerlo en términos situacionistas; 2) un espíritu de radicalismo político que se mezcla con una subversión juguetona, derivada del cuestionamiento de los métodos que se emplean para transformar nuestras relaciones con el entorno; y, 3 ) una exageración de lo misterioso y oscuro de la ciudad. ${ }^{11}$ Tres elementos que, dicho sea de paso, se encuentran presentes, de una forma u otra, en la obra de Guillermo Sheridan, que trata a la ciudad de México como centro de su crítica.

Para Debord, necesariamente se tiene que hacer una distinción entre la idea de ir a la deriva y, simplemente, pasear o viajar:

El concepto de deriva está ligado indisolublemente al reconocimiento de efectos de naturaleza psicogeográfica, y a la afirmación de un comportamiento lúdico-constructivo, lo que la opone en todos los aspectos a las nociones clásicas de viaje y de paseo. ${ }^{12}$

${ }^{11}$ Cfr. Merlin Coverley, Psycogeography, 2006, Harpenden, Pocket Essentials, pp. 12-4.

${ }^{12}$ Debord, "Théorie de la dérive", La Revue des Ressources, en línea, Internet julio 2009, disponible http://www.larevuedesressources.org. La traducción es de la editorial madrileña Literatura Gris, incluida en la antología Internacional situacionista: La realización del arte, disponible también en el Archivo Situacionista Hispano en línea http://www.sindominio.net.
Ir a la deriva implica una construcción, por medio de los sentidos, tanto del sendero que se está trazando como de lo que se observa; sin embargo, al mismo tiempo que se construye, se reconoce, pues todos ellos son elementos psicogeográficos sabidos. Esta dicotomía construcción-reconocimiento es una paradoja que el mismo Debord reconoce:

Pero la deriva, en su carácter unitario, comprende ese dejarse llevar y su contradicción necesaria: el dominio de las variables psicogeográficas por el conocimiento y el cálculo de sus posibilidades. Bajo este último aspecto, los datos puestos en evidencia por la ecología, aun siendo a priori muy limitado el espacio social que esta ciencia se propone estudiar, no dejan de ser útiles para apoyar el pensamiento psicogeográfico. ${ }^{13}$

Ir a la deriva, por tanto, implica que el caminante no puede descubrir algo novedoso en lo que observa, puesto que ya domina las variaciones psicogeográficas posibles; al mismo tiempo, la construcción instantánea de la ciudad (ya sea conocida o desconocida, es lo de menos) es novedad pura, descubrimiento absoluto. La ciudad, junto con el "derivante", transmuta en serpiente que se muerde la cola, bucle infinito de construcción y reconocimiento.

${ }^{13}$ Idem. 
NOTAS

Para Coverley, este acto de ir a la deriva en las urbes se convierte en sí en un acto de subversión, puesto que las ciudades se han convertido en espacios profundamente hostiles para los peatones, ${ }^{14}$ un acto que va en contra de la ciudad moderna:

Caminar se ve como algo que va en contra del espíritu de la ciudad moderna, ya que promueve una idea de circulación sin problemas y una mirada a nivel de piso que caminar requiere. Esto permite que uno cuestione la representación oficial de la ciudad al cortar las rutas establecidas y al explorar aquellas áreas marginales y olvidadas que, por lo general, son soslayadas por los habitantes de la ciudad. ${ }^{15}$

Esta manera de redescubrir, o reconstruir para ser más preciso, una ciudad queda aunada al segundo factor que Coverley apunta como elemental en el análisis psicogeográfico: la subversión.

"La psicogeografia", dice Coverley, "demuestra un sentido juguetón de provocación y engaño". ${ }^{16}$ La psicogeografía, desde sus inicios, buscaba crear algo más que una simple teoría estética o analítica, buscaba un cambio radical del mundo y, dado que queda construida a partir de la observación, de la forma en que se percibía

\footnotetext{
${ }^{14}$ Coverley, op. cit., p. 12.

${ }^{15}$ Idem.

${ }^{16}$ Ibid., p. 13.
}

la ciudad. Quizá derivadas de la famosa última tesis de las "Tesis sobre Feuerbach" de Karl Marx, ${ }^{17}$ Debord presentó sus propias "Thèses sur la révolution culturelle", documento en el que puede leerse que "El arte puede dejar de ser una relación de las sensaciones para convertirse en una organización directa de sensaciones superiores: se trata de producirnos a nosotros mismos, y no cosas que no nos sirvan". ${ }^{18}$ De tal manera, el acto mismo de apreciar conlleva creación: creación propia que deviene en alteración, o construcción, de la ciudad o del medio que rodea al "apreciador". Crear, en este sentido, necesariamente se entrelaza con los conceptos de rebelión, provocación y subversión, pues crear implica reconstruir, a partir de una suerte de radicalismo político, un edificio, una ciudad, un mundo, el universo entero.

Debord no hace hincapié sobre lo misterioso y oscuro de la ciudad, elemento característico de la psicogeografía de acuerdo a Coverley; sin embargo, el "Formulaire pour un urbanisme

17 "Los filósofos no han hecho más que interpretar de diversos modos el mundo, pero de lo que se trata es de transformarlo". Cfr. Karl Marx, Ludwig Feuerbach y el fin de la filosofia clásica alemana, en línea, Internet, disponible http://www. marxists.org.

${ }^{18}$ Debord, "Thèses sur la révolution culturelle." Internationale situationniste No. 1, junio 1958, en línea, Internet disponible http://www.debordiana. chez.com. La traducción al español también es de Literatura Gris, y está disponible en el Archivo Situacionista Hispano en línea http://www. sindominio.net. 
nouveau" de Ivan Chtcheglov, escrito bajo el pseudónimo de Gilles Ivain, describe en su párrafo introductorio la necesidad de redescubrir el misterio que solía guardar la ciudad:

Nos aburrimos en la ciudad, ya no hay ningún templo del sol. Entre las piernas de las mujeres que pasan, los dadaístas hubieran querido encontrar una llave inglesa y los surrealistas una copa de cristal. Esto se ha perdido. Sabemos leer en los rostros todas las promesas, último estado de la morfología. La poesía de los carteles ha durado veinte años. Nos aburrimos en la ciudad, tenemos que pringarnos para descubrir misterios todavía en los carteles de la calle, último estado del humor y de la poesía. ${ }^{19}$

El aburrimiento es lo que lleva, de acuerdo con Chtcheglov, a los letristas y posteriormente a los situacionistas a redescubrir el mundo por medio de la psicogeografía; por ello, es imperativo buscar en los rincones más oscuros y misteriosos de la ciudad aquellos elementos que han quedado olvidados, punto de partida para la reconstrucción de la ciudad mediante las distintas miradas y perspectivas que la constituyen.

${ }^{19}$ Ivan Chteglov, "Formulaire pour un urbanisme nouveau", en Chtcheglov Jean-Marie, Apostolidès y Boris Donné, Écrits retrouvés, 2006, París, Allia, p. 7. Esta traducción también es de la antología Internacional situacionista, disponible en línea http://www.sindominio.net.
Entendida grosso modo la psicogeografía y sus características principales, es posible ir a la deriva por la ciudad de México de Guillermo Sheridan. No son pocas las páginas que Sheridan le ha dedicado a esta ciudad, ni son pocas las maneras en que ha logrado retratarla. Aunque llenas de ironía y humor, sus descripciones son desgarradoras: crean una ciudad de México desoladora que se siente incómoda, precisamente por familiar y reconocible:

Cuando pasaban Mad Max hace años en los cines, con sus imágenes sobre lo espantoso que iba a ser el mundo posterior a la guerra atómica en el año cinco mil, los mexicanos nos sentíamos timados: hacía décadas que ese pinche futuro ya estaba en Iztapalapa y no cobraban por mirarlo. ${ }^{20}$

La ciudad de México de Sheridan es un lugar espantoso, oscuro, terrible, en el que cualquier cosa puede suceder, en la que el único misterio es que nada es misterioso (salvo cuando salen las cosas bien), una ciudad que es "rica en paradojas", erigida sobre un lago y muerta de sed. ${ }^{21}$ La de México es una ciudad que, para Sheridan, tiene la capacidad de presenciar cualquier cosa, incluso alcantarillas que

${ }^{20}$ Guillermo Sheridan, Viaje al centro de $m i$ tierra, 2011, Oaxaca, Almadía, p. 63.

${ }^{21}$ Cfr. ibid., p. 53. 
NOTAS

explotan, fenómeno que explica de la siguiente manera:

En pleno centro de la ciudad, luego de retumbar en sus centros la tierra un rato, varias alcantarillas lanzaron no agua (como es normal que sea anormal) sino unos elevados, ruidosos y potentes chorros de fuego... Supuse que más bien el fenómeno obedecía a que la hedionda diosa Coatlícue, que duerme bajo el estacionamiento de Bellas Artes, habría por fin lanzado un espantoso flato que llevaba cinco siglos cocinando. $^{22}$

Lo oscuro y misterioso de la ciudad quedan entremezclados con el humor y la ironía de Sheridan. La ciudad de México muestra lo anormal como cotidiano y lo sorprendente como cualquier cosa, incluso cuando exagerado se sabe normal, porque se encuentran diversos elementos psicogeográficos fácilmente reconocibles, aunque desoladores (Iztapalapa comparada con el mundo de Mad Max).

Así como Debord proponía que con el arte "se trata de producirnos a nosotros mismos", la ciudad de México en Sheridan busca la creación por medio de la reconstrucción, que involucra una reconfiguración nacional de identidad y personalidad. En su texto "Divisan complejo de

$$
{ }^{22} \text { Ibid., p. } 60 .
$$

inferioridad", distintos puntos de la ciudad de México son descritos de maneras peculiares, que suelen ser identificadas con la idea general de sentir orgullo por lo mexicano, por el simple hecho de ser mexicano:

- la Fuente de Petróleos, mundialmente celebrada como la más hermosa de América

- San Lázaro, una zona de la ciudad oriental que nadie entiende cómo no ha sido declarada patrimonio de la humanidad

- Plaza Garibaldi, sede internacional del aclamado mariachi mexicano

- el Zócalo, la plaza más bonita de la galaxia. ${ }^{23}$

Con estas descripciones, Sheridan hace burla de la vieja retórica nacionalista mexicana, aquella tan miedosa e insegura de sí que requiere reforzarse constantemente por sí misma. Sin embargo, esta ciudad de México es, sin duda, una de las múltiples capas de la ciudad de México: una capa que Sheridan bien podría eliminar y que poco sentido tiene para él. En este sentido, puede identificarse la subversión que proponía Debord, identificada por Coverley como inherente a la psicogeografía: Sheridan no sólo se burla de una actitud mexicana que detesta, paralelamente está proponiendo eliminarla de $s u$ ciudad

\footnotetext{
${ }^{23}$ Ibid., pp. 49-50. Las itálicas son mías.
} 
de México, mediante su inclusión en la burla a esa ciudad de México.

Este "radicalismo" de Sheridan, para hacer uso de terminología situacionista, llega a entrelazarse con sus retratos exagerados de la oscuridad y lo decadente de la ciudad de México, como se puede ver en "Cuando el futuro nos alcance":

El canal del desagüe se va a salir de madre y se va a inundar de mierda la ciudad, y va a haber que adaptarse a vivir así como en Xochimilco y las peseras van a ser como las bananas de Acapulco [...] y Ebrard va a hacer segundos pisos para las lanchas rápidas y las manifestaciones van a ser de pura gente metida en guajes o llantas [...] y Ebrard dirá que rechaza la ayuda federal porque es una intromisión [...] y dirá que la del DF sería mierda pero mierda orgullosa de ser libre. ${ }^{24}$

Las descripciones francamente nauseabundas de lo que podría llegar a ser la ciudad en un futuro (si no lo es ya, por agosto y septiembre de cada año) quedan enmarcadas, además, por un fuerte y contundente argumento político y social de Sheridan. De tal manera, en su ciudad quedan enfrascados elementos psicogeográficos que crean, reconstruyen y además reconocen a una ciudad de

${ }^{24}$ Ibid., p. 65.
México bastante peculiar e interesante; sugerente, en particular, por su capacidad de presentarse como incómoda frente a quien la lee (porque también la vive).

Si bien la deriva a pie no es punto fundamental en los ensayos de Sheridan que se encargan de la ciudad de México (aunque sí de sus ensayos sobre la provincia en México, tema quizá para otra ocasión), el paseo en auto sí es frecuente. Las nociones de la teoría de la deriva de Debord no encuadran a la perfección con los textos de Sheridan; sin embargo, considerando que la ciudad de México es en sí un caso particular frente a las demás metrópolis del mundo, se podría considerar que la deriva en ella también debería saberse particular o distinta. Propongo que se pueda considerar un trayecto delimitado y cotidiano como acto de ir a la deriva porque pensar que así suceda (planeado y bien delimitado) en la ciudad de México es, aunque posible, poco probable. Esto queda representado en el párrafo final de "La mañana está bonita", una suerte de crónica que relata todo lo que le sucede a Sheridan entre las 9:40 AM y las 10:18 AM, entre la puerta de su casa y el estacionamiento de su trabajo, mientras maneja: "En un trayecto de nueve kilómetros casi me chocan cuatro veces, me mentaron la madre tres, vi una ametralladora de cerca, me tardé treinta 
NOTAS

y ocho minutos. Ojalá siempre me fuera así de bien". ${ }^{25}$ En la ciudad de México de Sheridan, en un trayecto definido, corto incluso, va uno necesariamente a la deriva, pues todo puede pasar. Lo único que puede cambiar esto es un "pinche viru", como el que puso a la ciudad de México "en peligro" hace algunos años, cuando manejando por las calles, a Sheridan le "llama la atención que la gente maneja con cuidado. El pánico es lo único que hace cortés al mexicano". ${ }^{26}$ Así, en la ciudad de México de Sheridan, y en muchas otras, el "derivante" siempre va a la deriva, aunque vaya en auto, caminando, de paseo o con una ruta bien delimitada.

Este modo de ir a la deriva le permite a Sheridan vivir la arquitectura y la ciudad de maneras muy específicas. Robert Alter afirma que las descripciones narrativas de las ciudades permiten apreciar "el pulso cambiante de la experiencia del individuo, cómo la mente y sus sentidos se apoderan del mundo, lo construyen $\mathrm{o}$, en ocasiones, se confunden y entremezclan con él"; $; 2$ sin embargo, la ciudad de México de Sheridan permite apreciar estos cambios por

${ }^{25}$ Sheridan, Lugar a dudas, 2000, México, Tusquets, p. 103.

${ }^{26}$ Sheridan, Viaje..., p. 28.

${ }^{27}$ Robert Alter, Imagined Cities: Urban Experience and the Language of the Novel, 2005, New Haven, Yale University Press, p. xi. medio del ensayo. Así, sugiere Julian Murphet en "Postmodernism and space".

Cuando cada edificio o paisaje urbano es en sí un simulacro, un pastiche divertido o cita de algún original apócrifo y ausente, nosotros que habitamos esos espacios somos "hiperrealizados", apenas nos damos cuenta de que somos extras en el escenario de una narrativa cuasihollywoodense que nos elude. ${ }^{28}$

Las descripciones, peculiares ellas, de distintos aspectos arquitectónicos de la ciudad en la obra de Sheridan, dejan ver cómo configuran a Sheridan mismo y su opinión sobre el entorno, como se lee en "Mis vecinos": "En la medida en que crece la familia, los Valdós le agregan pisos a su casa: un bodoque de cinco pisos estilo heterodoxo con ventanas doradas en cuya planta baja funciona la Estética Unisex Erikha Mónikha". ${ }^{29}$ Asimismo, la misma familia Valdós se vuelve parte de la experiencia psicogeográfica de Sheridan en su ciudad, que queda reflejada en su representación de la colonia en la que vive: "los hombres en edad de reproducirse se sientan sin camisa en la

${ }^{28}$ Julian Murphet, "Postmodernism and space", en Steven Connor (ed.), The Cambridge Companion to Postmodernism, 2004, Cambridge, Cambridge University Press, p. 119.

${ }^{29}$ Sheridan, Lugar ..., p. 98. 
calle a hacer concursos de a ver quién se acaba primero su Tecate y luego ver quién es capaz de sostener el bote vacío más tiempo, estando de pie, con el ombligo". ${ }^{30}$ Personas y arquitectura quedan fusionadas ante los ojos de Sheridan, en su ciudad de México, pues ambos quedan impactados de igual manera en su pluma, como pasa con el club nocturno de otro de sus vecinos:

La discohteque El Reve originalmente era un cuarto de servicio que queda justo debajo de mi ventana. Su administrador y único cliente es un joven de dieciocho años al que apoda "El Eskín", porque se rapa las salpicaderas, como se llama la zona del cráneo que está sobre las orejas. ${ }^{31}$

Toda experiencia con sus vecinos queda enmarcada por una reconfiguración del espacio de Sheridan. Toda experiencia con sus vecinos se convierte en comentario social y construcción de la ciudad de México en su totalidad. Toda experiencia con sus vecinos recuerda al lector lo fácil que es encontrar esa ciudad de México, que dista mucho de ser de vanguardia o de esperanza.

Doreen Massey define a la ciudad como "intersecciones de narrativas múltiples, como nexos de historias sincrónicas", ${ }^{32}$ espacio siempre individual, siempre colectivo, íntimo y a la vez público, anida en distintas esferas que parecen incomprensibles, en la mayoría de los casos y que sólo puede ser explicada, hasta cierto punto, a partir de la polifonía de significantes que presenta. Eso es la ciudad de México ante los ojos de Sheridan: un cruce de infinitos senderos y posibilidades innumerables.

En esa ciudad de México, que bien puede ser cualquiera, lo poco probable no sólo es posible, sino que es, además, esperable. En el ir a la deriva de Sheridan se encuentra una plétora de posibilidades psicogeográficas, yuxtapuestas y entrelazadas, que permiten entender a una ciudad de México más compleja, y mucho más bonita que la que la Guía Roji puede ofrecer.
${ }^{30}$ Idem.

${ }^{31}$ Ibid., p. 99.
${ }^{32}$ Cfr. Peter Brooker, Modern Metropolis: Writing, Film and Urban Formations, 2002, Nueva York, Palgrave, p. 1. 
CITAM Derechos Reservados.

La reproducción total o parcial de este artículo se podrá hacer si el ITAM otorga la autorización previamente por escrito. 